\title{
Triploid Induction of Green Tiger Shrimp, Penaeus semisulcatus (De Haan, 1844) Using Temperature and Chemical Shock
}

\author{
Mehmet K1R ${ }^{1}$ AND GöKhan TARHAN \\ Faculty of Fisheries, Mugla Sitki Kocman University, 48000 Kotekli, Mugla, Turkey \\ ÖZGür OKUR \\ Izmir Institute of Technology, Biotechnology and Bioengineering Central Research Laboratories \\ Gulbahce, Campus 35430, Urla, Izmir, Turkey
}

\begin{abstract}
Triploidy in fertilized eggs of Penaeus semisulcatus was induced by temperature and chemical shocks. The eggs, which were obtained from the shrimp broodstock maintained at $29 \mathrm{C}$, were exposed to cold temperature $(8,10,12$, and $14 \mathrm{C})$ and 6-dimetiloaminopurine (6-DMAP) concentrations $(100,150,200$, and $250 \mu \mathrm{M})$ for different durations $(4,6$, and $8 \mathrm{~min}) 9 \mathrm{~min}$ after spawning was detected. While the highest triploidy rate of $49.7 \pm 4.5 \%$ was obtained with a $200 \mu \mathrm{M}$ 6-DMAP concentration for a duration of $8 \mathrm{~min}$, the best mean triploidy rate of $45.5 \pm 2.8 \%$ for cold shock was obtained at a temperature of 10 $C$ for a duration of $8 \mathrm{~min}$. Temperature and 6-DMAP concentration did not have significant effect on triploidy rate $(P>0.05)$ but shock duration had significant effect on triploidy rate for individual cold temperature shock or 6-DMAP chemical shock $(P<0.05)$. Although longer durations of shock agent increased the rates of triploid induction, they generally had an adverse effect on hatching rates in the study.
\end{abstract}

Induction of triploidy is the most commonly used technique that has been investigated in shrimp that has the potential to protect breeders' rights through conferring reproductive sterility (Sellars et al. 2012b). Triploid inductions have been successful in penaeid shrimp using a variety of shock agents including temperature (heat and cold) (Dumas and Ramos 1999; Li et al. 2003; Aloise et al. 2011; Kir et al. 2014) and chemicals (6-dimetiloaminopurine [6-DMAP] and cytochalasin B) (Bao et al. 1994; Norris et al. 2005; Sellars et al. 2006a). Triploidy induction methods are made up of a combination of a shock agent, magnitude of shock, timing of the shock, and duration of the shock (Sellars et al. 2010). Two categories of triploidy have been studied in penaeid shrimps: meiosis I and meiosis II triploidy. In these categories, triploid shrimps are induced by inhibiting the extrusion of the first polar body (PBI), or the second polar body (PBII) during meiosis. Chemical

\footnotetext{
${ }^{1}$ Correspondence to: mkir@mu.edu.tr
}

or temperature shock is commonly used to produce meiosis I or II triploids in penaeid shrimp (Li et al. 2003, 2006; Sellars et al. 2006a, 2010). Important research on triploid induction of several shrimp species has been conducted so far around the world. The most studied species are Fenneropenaeus chinensis, Litopenaeus vannamei, Marsupenaeus japonicus, and Penaeus monodon (see Sellars et al. 2010). Triploid induction has also been successful but less intensively studied in Fenneropenaeus indicus (Morelli and Aquacop 2003), Metapenaeus ensis (Zhou et al. 1999; Zhang 2001) and Melicertus kerathurus (Kir et al. 2014).

Meiotic I triploid $F$. chinensis are reliably produced by applying a temperature shock at 4-10 min after spawning for a 10-min duration (Li et al. 2006). In comparison, meiotic I triploid M. japonicus are reliably produced by applying a shock at 1-2 min after spawning for a 6-min duration (Sellars et al. 2006b). While meiotic II triploids are reliably produced in $F$. chinensis by applying the shock 20-30 min after spawning 
for a duration of $10 \mathrm{~min}$ ( $\mathrm{Li}$ et al. 2003). Meiotic II triploids are reliably produced by applying the shock 7-8 min after spawning for a duration 2-15 min in M. japonicus (Norris et al. 2005; Coman et al. 2008), P. monodon (Wood et al. 2011; Pongtippatee et al. 2012; Sellars et al. 2012a) and L. vannamei (Sellars et al. 2012b).

Penaeus semisulcatus is an Indo-Pacific shrimp species distributed along the coast of the Eastern Mediterranean Sea. It is one of the most important and appropriate shrimp species for aquaculture in subtropical regions (Kır and Kumlu 2006). Triploid induction of $P$. semisulcatus has not been studied to date. In this study, triploidy was induced in P. semisulcatus embryos using cold temperature shock and 6-DMAP chemical shock induction to stop first or second meiotic division (PBI or PBII extrusion). The study was undertaken to determine the effectiveness of shock agent and shock duration on triploidy induction in P. semisulcatus.

\section{Materials and Methods}

\section{Broodstock, Spawning, and Embryo Collection}

The broodstock shrimp required for spawning in the study were obtained from a wild population off the North Eastern Mediterranean coast of Turkey $\left(36^{\circ} 43^{\prime} \mathrm{N}, 35^{\circ} 46^{\prime} \mathrm{E}\right)$. The broodstock were kept in $1500 \mathrm{~L}$ maturation tanks supplied with sea water maintained at 29 C. Twice daily the shrimp were fed crab and mussels. Gravid females were individually put into $50 \mathrm{~L}$ circular spawning tanks. The tanks contained a manipulation basket (500 $\mu \mathrm{m}$ mesh size) placed inside egg collectors (100 $\mu \mathrm{m}$ mesh size). The temperature and salinity of the water in the spawning tanks were $29 \mathrm{C}$ and $36 \mathrm{ppt}$, respectively. In order to determine the time of spawning, the shrimp in the spawning tank was consistently observed by a night vision camera connected to computer. After the shrimp had spawned, the manipulation basket was suspended to remove spermatophores and excrement debris.

\section{Triploidy Induction}

Prior to the triploid induction, microscopic observations were carried out to determine the timing of PBI and PBII extrusions (Chavez et al. 1991; Garnica-Rivera et al. 2004). A total of 216 triploid induction treatments with a control were carried out with embryos from four separate spawnings at a salinity of $36 \mathrm{ppt}$. The treatments were conducted using cold temperature $(8,10,12$ and, 14 C) and 6-DMAP (100, $150,200$, and $250 \mu \mathrm{M})$ shock with three shock durations (4, 6, and $8 \mathrm{~min})$. All experimental treatments were replicated twice with a control (29 C). After spawning, the fertilized eggs were distributed into $200 \mathrm{~mL}$ plastic shock containers (PSC). Each PSC contained about 650 eggs. The bottom and top of the PSC were covered with a $100-\mu \mathrm{m}$ mesh screen. In accordance with the experimental design, the PSCs that held shrimp eggs were submerged in the water baths that contained different temperatures of water and different concentrations of 6-DMAP to perform the cold temperature shocks and chemical shocks. The treatment began $9 \mathrm{~min}$ after spawning. After shock, the PSCs with eggs were then returned directly to clean sea water (29 C).

\section{Determining of Hatching Rate}

About $15 \mathrm{~h}$ after spawning, five egg aliquots $(10 \mathrm{~mL})$ from each treatment (each PSC) were removed. The rate of hatched eggs was calculated by establishing the total number of eggs in the PSC and the relative frequencies of hatched eggs and nonhatched eggs in the distinct thermal and chemical shock treatments.

\section{Assessment of Triploidy}

The nauplii samples were disintegrated in 1 $\mathrm{mL}$ marine phosphate buffered solution (MPBS) containing $0.1 \%$ Triton $\mathrm{X}-100(11 \mathrm{~g} / \mathrm{L} \mathrm{NaCl}$, $0.2 \mathrm{~g} / \mathrm{L} \mathrm{KCl}$, and $\left.1.15 \mathrm{~g} / \mathrm{L}_{2} \mathrm{Na}_{2} \mathrm{HPO}_{4} \quad 2 \mathrm{H}_{2} \mathrm{O}\right)$ and then homogenized by passing through a 25 -gauge needle. Samples were pushed against the wall of the tube firmly eight times and the cell suspension passed through and $80-\mu \mathrm{m}$ mesh to obtain single cells (Sellars et al. 2006a). Hundred microliters RNase A $(200 \mu \mathrm{g} / \mathrm{mL})$ was added for each sample. After $30 \mathrm{~min}$ of incubation at $37 \mathrm{C} 100 \mu \mathrm{L}$ propidium iodide (PI) $(1 \mathrm{mg} / \mathrm{mL})$ stain was added and incubated for 15 

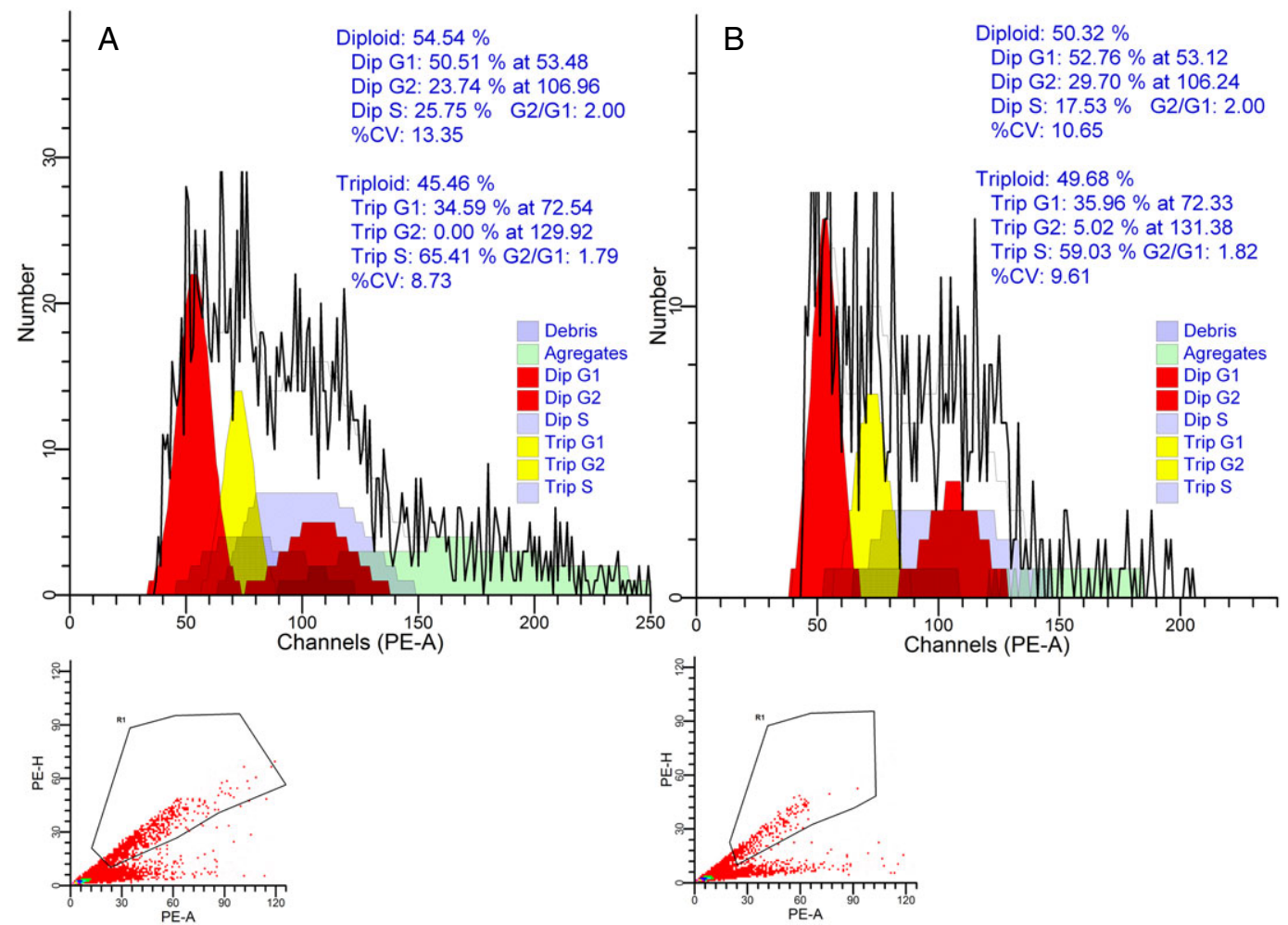

FIGURE 1. The fluorescence-activated cell sorting (FACS) data output to detect the highest triploid rate from (A) cold temperature of $10 \mathrm{C}$ and (B) 6-dimetiloaminopurine (6-DMAP) shock of $200 \mu M$ for a duration of 8 min for spawning 4.

min at room temperature in the dark. The ploidy assessment of the samples was performed by fluorescence-activated cell sorting (FACS) using a flow cytometer (Beckton Dickinson Immunocytometry Systems, San Jose, CA, USA). To detect PI, a green solid state 488 laser was used for excitation, and a 556/LP and 585/40 configuration was used for detection. The level of triploidy in each sample was then determined using ModFit LT software (Verity Software House, Topsham, ME, USA).

\section{Statistical Analysis}

The effect of temperature, 6-DMAP concentration and shock duration on triploid and hatch rates were analyzed by ANOVA using SPSS 15.0. Regression analyses were subsequently performed to determine the relationship between shock duration and triploid rates using the Microsoft Excel program.

\section{Results and Discussion}

In this study, triploidy induction was performed on $P$. semisulcatus embryos using cold temperature shocks or 6-DMAP chemical shocks in a progressive factorial experiment. Prior to the experiment, the extrusion of PBI and PBII in eggs of $P$. semisulcatus at $29 \mathrm{C}$ were observed within 4-6 and 10-16 min post spawning, respectively. Higher frequency of extrusion occurred at 5 and $15 \mathrm{~min}$. These results are slightly different from those reported in previous studies for M. kerathurus (4-16 min) (Kır et al. 2014) and L. vannamei (8-15 min) (Dumas and Ramos 1999) but, similar to those reported for $M$. japonicus (4-15 min) (Norris et al. 2005) and P. monodon (5-15 min) (Pongtippatee-Taweepreda et al. 2004). Sellars et al. (2012a) got meiosis I or meiosis II triploid of L. vannameii using $200 \mu \mathrm{M}$ 6-DMAP shock at 1 and $7 \mathrm{~min} 30 \mathrm{~s}$ post spawning, respectively. Sellars et al. (2012b) applied chemical shock 

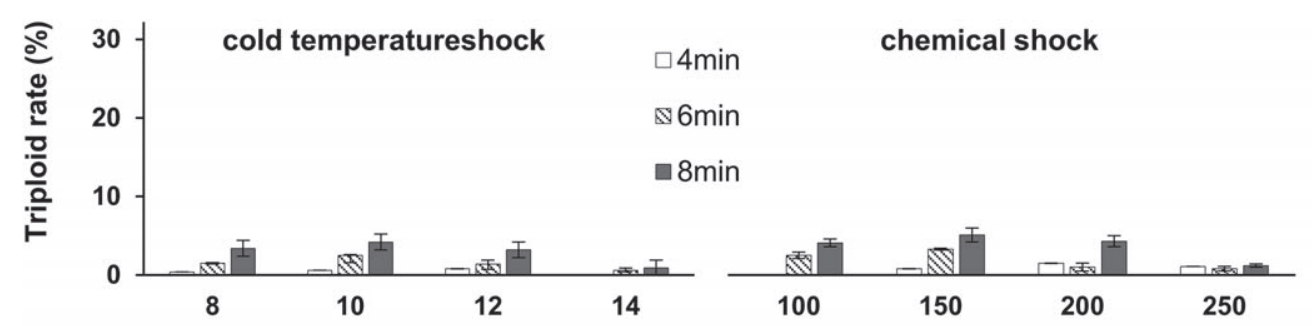

chemical shock
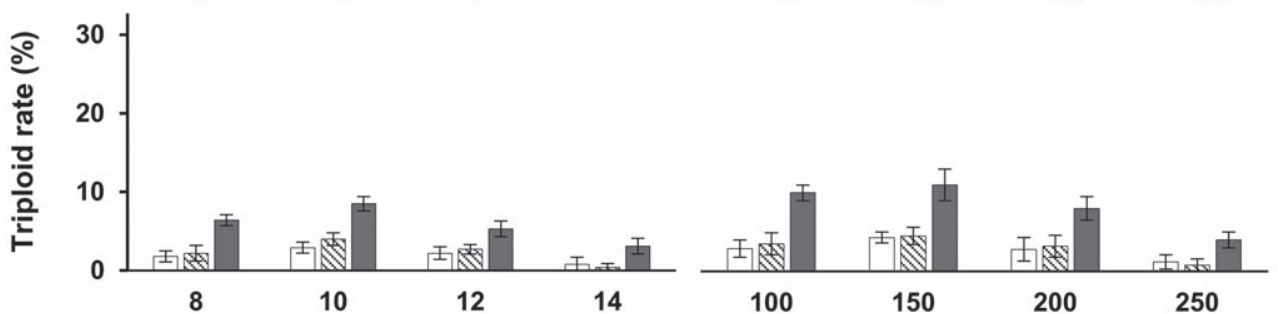

№
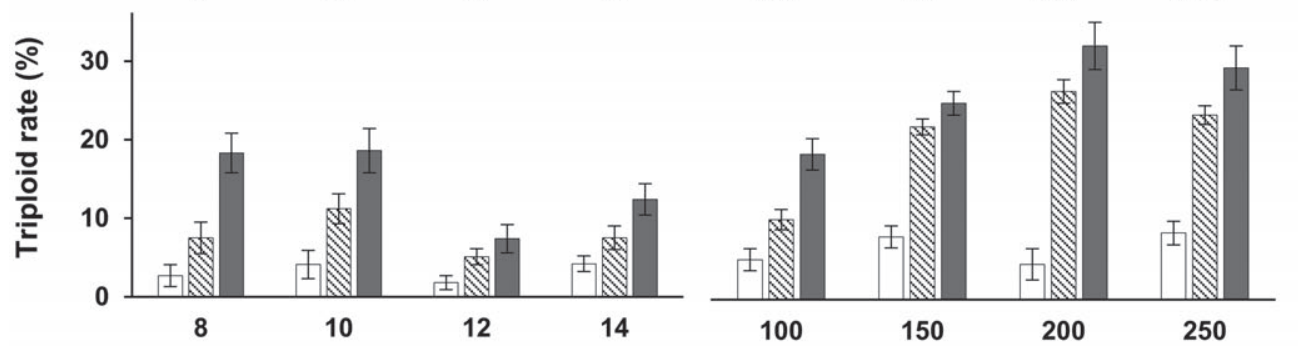

के
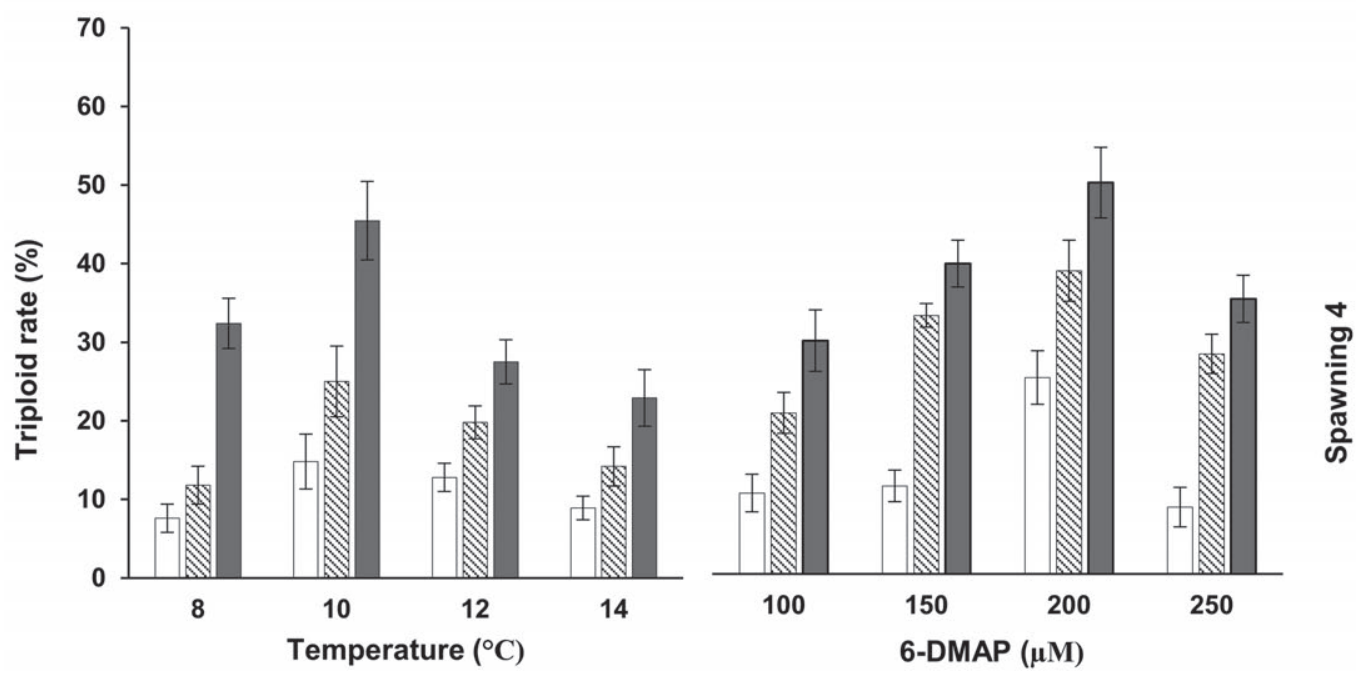

FIGURE 2. Triploid induction rates [mean \pm standard error (SE)\%] of Penaeus semisulcatus nauplii from four spawning when subjected to different cold temperatures shock $(C)$ and different 6-dimetiloaminopurine (6-DMAP) shock $(\mu M)$ at durations of 4, 6, and 8 min.

(6-DMAP) to eggs of $P$. monodon after $6 \mathrm{~min}$ and $40 \mathrm{~s}$ spawning to get meiosis I and meiosis II triploid. Pongtippatee et al. (2012) reported that meiosis II triploids $(61.4 \%)$ of $P$. monodon were induced when cold shock at $8 \mathrm{C}$ was applied at
$10 \mathrm{~min}$ post spawning for duration of $10 \mathrm{~min}$. Kir et al. (2014) produced meiosis I and meiosis II triploids of $M$. kerathurus using cold shock at $10 \mathrm{~min}$ post spawning at $10 \mathrm{C}$ for a duration of $8 \mathrm{~min}$. In this study cold temperature shocks 

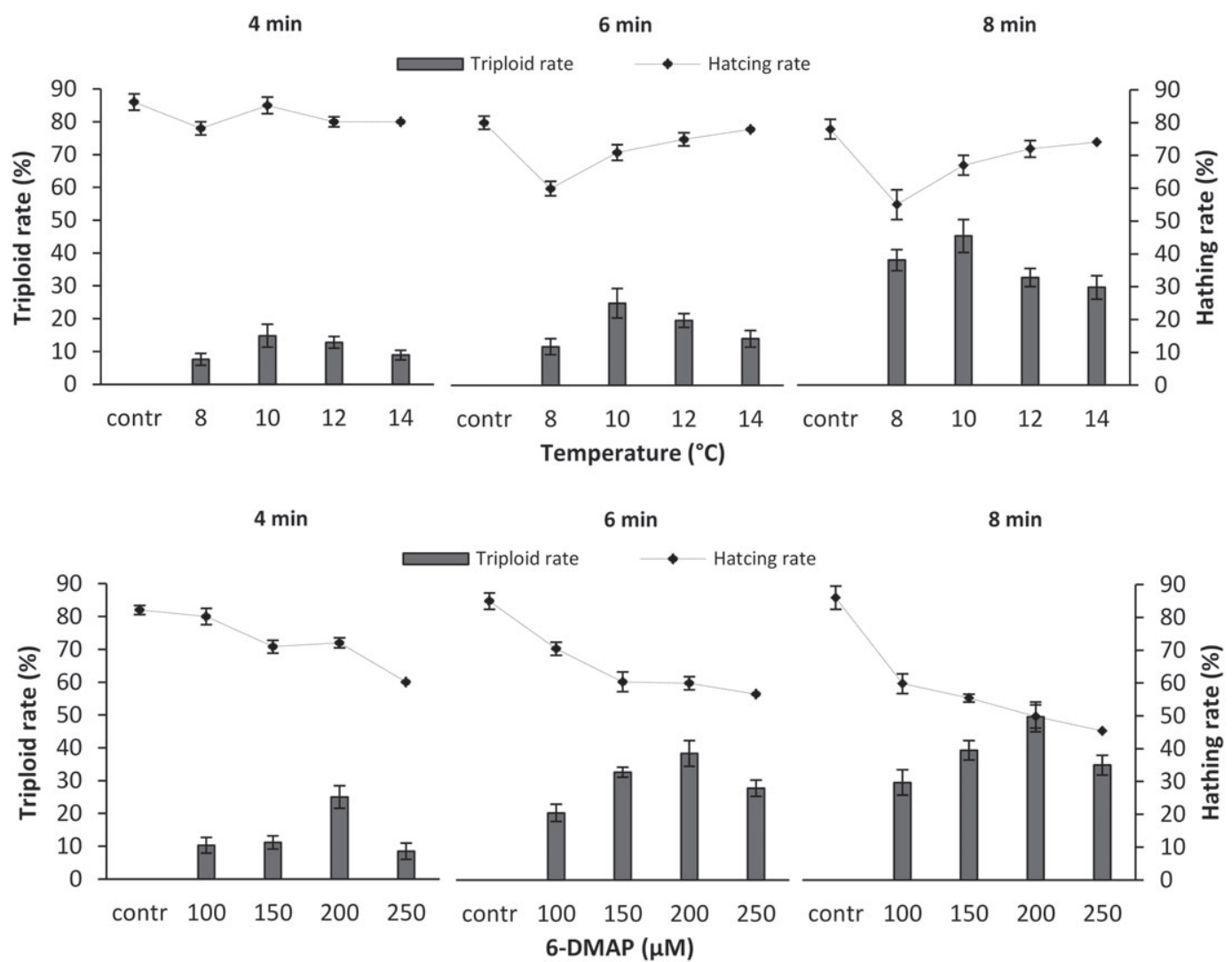

FIGURE 3. Relationship between the induction and hatching rates (mean \pm standard error (SE)\%) from spawning four at different cold temperatures shock $(C)$ and 6-dimetiloaminopurine (6-DMAP) shock ( $\mu M)$ for durations of 4, 6, and 8 min.

and 6-DMAP shocks were applied 9 min after spawning. Because the spawning duration of the gravid shrimp is several minutes, triploids induced using shock agents in this study might be meiosis I and mostly meiosis II triploids.

The best individual cold shock treatment, in this study, produced $45.5 \%$ triploid nauplii in spawning 4, using a temperature of $10 \mathrm{C}$ for an 8-min duration (Fig. 1A). Dumas and Ramos (1999) and Aloise et al. (2011) have reported triploid inductions of up to $100 \%$ in another penaeid shrimp, L. vannamei, using a cold shock temperature of $10 \mathrm{C}$, the same as the most successful individual induction rate in this study. This induction temperature is similar to those reported in previous studies for $P$. monodon (76.7\%; Wood et al. 2011) and for M. kerathurus (64.5\%; Kir et al. 2014). The highest individual treatment produced $49.67 \%$ triploid nauplii in spawning 4 using 6-DMAP $(200 \mu \mathrm{M})$ for an 8-min duration in the current study (Fig. 1B). 6-DMAP has also been successfully used to produce viable meiosis I and II triploids in M. japonicus (Sellars et al. 2006a), P. monodon (Sellars et al. 2012b) and L. vannamei (Sellars et al. 2012a) with similar optimal induction parameters. Regression analyses for individual cold temperature or 6-DMAP applications for all spawning in the current study determined that the level of shock agent did not have a significant effect $(P>0.05)$ on triploid induction rate. However, triploidy rates obtained from 6-DMAP shock were significantly higher $(P<0.05)$ than those obtained from cold temperature shock (Fig. 2). Across all shock durations, triploid nauplii induction rates ranged between $0-49.7 \%$ and $0-45.5 \%$ for 6-DMAP shock and cold temperature shock, respectively. 
Induction rate increased for each longer shock duration in the study. While duration of shock application had a significant impact $(P<0.05)$ on induction rates in spawning 3 and 4 , duration of shock application had no significant impact $(P$ $>0.05)$ on triploid induction rates in spawning 1 and spawning 2 (Fig. 2). It is well accepted that the percentage of triploids induced in any spawning is dependent on several variables including the shock agent, timing, and duration of the shock. Percentage induction also differs because spawning lasts several minutes, so embryo development is asynchronous and water temperature and chemistry may change over the duration of the spawning (Sellars et al. 2010).

In this study, the mean hatching rates, for the most successful induction treatments, were $85 \%$ for 6-DMAP shock and $80 \%$ for cold temperature shock. The hatching rate of fertilized eggs after chemical shock or temperature shock was directly related to the duration time of the shock application. Statistical analysis indicated that duration had a significant $(P<0.05)$ effect on the hatching rate at all treatment levels. Although longer shock durations of cold temperature and 6-DMAP application increased the rates of triploid induction, they generally had an adverse effect on hatching rates in the study (Fig. 3). Across all shock durations hatching rates ranged between 62 and $85 \%$ for cold temperature shock, 45 and $80 \%$ for 6-DMAP shock and 78 and $86 \%$ for control.

The results of this study indicate that, similar to other penaeid shrimps, production of triploid individuals of $P$. semisulcatus is possible. This study demonstrates that, owing to a wide variety of effective parameters, it is essential to optimize shock conditions for each species. The findings of this research can help researchers and producers improve the aquaculture industry by producing triploid P. semisulcatus.

\section{Acknowledgments}

This study was financed with funding from The Scientific and Technological Research Council of Turkey (Project \#: 1090431) and the Scientific Research Projects of Mugla Sitki Kocman University (Project \#: 2011-2).

\section{Literature Cited}

Aloise, D. A., F. A. Maia-Lima, R. M. Oliveira, T. M. Cabral, and W. F. Molina. 2011. Ploidy manipulation and polyploid detection in the white shrimp Litopenaeus vannamei (Boone1931) (Decapoda, Penaeidae). Marine Biotechnology 13:41-47.

Bao, Z., Q. Zhang, H. Wang, and J. Dai. 1994. Cytochalasin B induced triploidy in Penaeus chinensis. Acta Oceanologica Sinica 13:261-267.

Chavez, J. C., M. Murofushi, K. Aida, and I. Hanyu. 1991. Karyological studies on the freshwater prawn Macrobrachium rosenbergii. Aquaculture 97:327-334.

Coman, F. E., M. J. Sellars, B. J. Norris, G. J. Coman, and N. P. Preston. 2008. The effects of triploidy on Penaeus (Marsupenaeus) japonicus (Bate) survival, growth and gender when compared to diploid siblings. Aquaculture 276:50-59.

Dumas, S. and R. Ramos. 1999. Triploidy induction in the Pacific white shrimp Litopenaeus vannamei (Boone). Aquaculture Research 30:621-624.

Garnica-Rivera, C., J. L. Arredondo-Figueroa, and I. L. A. Barriga-Sosa. 2004. Optimization of triploidy induction in the Pacific White Shrimp, Litopenaeus vannamei. Journal of Applied Aquaculture 16:85-94.

Kır, M. and M. Kumlu. 2006. Acute toxicity of ammonia to Penaeus semisulcatus post-larvae in relation to salinity. Journal of the World Aquaculture Society 37(2):231-235.

Kır, M., A. K. Şahan, and Ö. Okur. 2014. Induction of triploidy in Melicertus kerathurus (Forskal, 1775) with temperature shock. Aquaculture Research. DOI: $10.1111 /$ are.12464.

Li, F., J. Xiang, L. Zhou, C. Wu, and X. Zhang. 2003. Optimization of triploid induction by heat shock in Chinese shrimp Fenneropenaeus chinensis. Aquaculture 219:221-223.

Li, F., C. Zhang, K. Yu, X. Liu, X. Zhang, L. Zhou, and J. Xiang. 2006. Larval metamorphosis and morphological characteristic analysis of triploid shrimp Fenneropenaeus chinensis (Osbeck, 1765). Aquaculture Research 37:1180-1186.

Morelli, M. and Aquacop . 2003. Effects of heat shock on cell division and microtubule organization in zygotes of the shrimp Penaeus indicus (Crustacea, Decapoda) observed with confocal microscopy. Aquaculture 216:39-53.

Norris, B. J., F. E. Coman, M. J. Sellars, and N. P. Preston. 2005. Triploid induction in Penaeus japonicus (Bate) with 6-dimethylaminopurine. Aquaculture Research 36:202-206.

Pongtippatee, P., K. Laburee, P. Thaweethamsewee, R. Hiranphan, S. Asuvapongpatana, W. Weerachatyanukul, T. Srisawat, and B. Withyachumnarnku. 2012. Triploid Penaeus monodon: sex ratio and growth rate. Aquaculture 356-357:7-13.

Pongtippatee-Taweepreda, P., J. Chavadej, P. Plodpai, B. Pratoomchart, P. Sobhon, W. Weerachatyanukul, and B. Withyachumnarnkul. 2004. Egg activation in 
the black tiger shrimp Penaeus monodon. Aquaculture 234:183-198.

Sellars, M. J., B. M. Degnan, and N. P. Preston. 2006a. Induction of triploid Kuruma shrimp, Marsupenaeus (Penaeus) japonicus (Bate) nauplii through inhibition of polar body I, or polar body I and II extrusion using 6-dimethylaminopurine. Aquaculture 256: 337-345.

Sellars, M. J., B. M. Degnan, and N. P. Preston. 2006b. Recent advances in Marsupenaeus japonicus polyploidy induction: mitotic tetraploidy and polar body I triplody. World Aquaculture 2006: Book of Abstract, Frienze, Italy.

Sellars, M. J., F. Li, N. P. Preston, and J. Xiang. 2010. Penaeid shrimp polyploidy: global status and future direction. Aquaculture 310:1-7.

Sellars, M. J., A. Wood, B. Murphy, R. M. McCulloch, and N. P. Preston. 2012a. Triploid Black Tiger shrimp
(Penaeus monodon) performance from egg to harvest age. Aquaculture 324-325:242-249.

Sellars, M. J., S. M. Arce, and P. L. Hertzler. 2012b. Triploidy induction in the Pacific White Shrimp Litopenaeus vannamei: an assessment of induction agents and parameters, embryo viability, and early larval survival. Marine Biotechnology 14:740-751.

Wood, A. T., G. J. Coman, A. R. Foote, and M. J. Sellars. 2011. Triploid induction of black tiger shrimp, Penaeus monodon (Fabricius) using cold shock. Aquaculture Research 42:1741-1744.

Zhang, X. J. 2001. Study on the chromosome and polyploid induction in some Penaeid shrimps. PhD thesis, Institute of Oceanology, Chinese Academy of Sciences, Qingdao, China.

Zhou, L., T. Deng, X. Zhang, K. Yu, and J. Xiang. 1999. Detection of ploidy in shrimp by flow cytometry. Marine Science 2:42-46. 